\title{
Effects of virtual reality therapy on upper limb function after stroke and the role of neuroimaging as a predictor of a better response
}

\author{
Efeitos da terapia de realidade virtual na função do membro superior após AVC e o papel \\ da neuroimagem como preditor de melhor resposta \\ Maicon Gabriel Gonçalves', Mariana Floriano Luiza Piva', Carlos Leonardo Sacomani Marques', Rafael \\ Dalle Molle da Costa17, Rodrigo Bazan³, Gustavo José Luvizutto², Luiz Eduardo Gomes Garcia Betting³
}

\begin{abstract}
Background: Virtual reality therapy (VRT) is an interactive intervention that induces neuroplasticity. The aim was to evaluate the effects of VRT associated with conventional rehabilitation for an upper limb after stroke, and the neuroimaging predictors of a better response to VRT. Methods: Patients with stroke were selected, and clinical neurological, upper limb function, and quality of life were evaluated. Statistical analysis was performed using a linear model comparing pre- and post-VRT. Lesions were segmented in the post-stroke computed tomography. A voxel-based lesion-symptom mapping approach was used to investigate the relationship between the lesion and upper limb function. Results: Eighteen patients were studied ( $55.5 \pm 13.9$ years of age). Quality of life, functional independence, and dexterity of the upper limb showed improvement after VRT ( $p$ 0.001). Neuroimaging analysis showed negative correlations between the internal capsule lesion and functional recovery. Conclusion: VRT showed benefits for patients with stroke, but when there was an internal capsule lesion, a worse response was observed.
\end{abstract}

Keywords: Stroke; neuroimaging; virtual reality exposure therapy.

\begin{abstract}
RESUMO
Introdução: A realidade virtual (RV) é uma intervenção interativa que induz a neuroplasticidade. O objetivo deste estudo foi avaliar os efeitos da RV associado à reabilitação convencional na função do membro superior após o AVC e as características preditores de neuroimagem de melhor resposta a esta terapia. Métodos: os pacientes com AVC foram selecionados, e as características neurológicas, a função do membro superior e a qualidade de vida foram avaliadas. A análise estatística foi realizada por meio de modelo linear geral comparando resultados pré e pós-intervenção. As lesões foram segmentadas na tomografia computadorizada após o AVC. A abordagem de mapeamento da lesãosintoma baseada em voxel foi utilizada para avaliar a relação entre a lesão e a função do membro superior. Resultados: Foram estudados 18 pacientes ( 8 mulheres, $55,5 \pm 13,9$ anos). A qualidade de vida, independência funcional, características funcionais e destreza do membro superior apresentaram melhora após RV ( $<$ 0,001). A análise de imagem mostrou correlações negativas principalmente entre a cápsula interna e a recuperação funcional do membro superior. Conclusão: A RV mostrou benefícios para pacientes com AVC, mas quando houve lesão da cápsula interna apresentaram pior resposta à terapia.
\end{abstract}

Palavras-chave: Acidente vascular cerebral; neuroimagem; terapia de exposição à realidade virtual.

Stroke can be defined as a neurological deficit resulting from focal and acute central nervous system injury. It is considered a major cause of mortality and disability worldwide ${ }^{1}$. Stroke is the second leading cause of death in Brazil and the leading cause of chronic disability in adults, resulting in socioeconomic consequences and reduced quality of life. Therefore, it is an important public health problem, particularly because of long-term dependence on public health services ${ }^{2,3}$.

Cerebrovascular injury may damage the cells of the cortex and emerging axons, generating dysfunction of the upper motor neurons. Motor function can be impaired, reducing functional capacity, particularly that of the upper limbs ${ }^{4}$.

\footnotetext{
${ }^{1}$ Universidade Estadual Paulista, Faculdade de Medicina de Botucatu, Botucatu SP, Brasil;

${ }^{2}$ Universidade Federal do Triângulo Mineiro, Departamento de Fisioterapia Aplicada, Uberaba MG, Brasil;

${ }^{3}$ Universidade Estadual Paulista, Faculdade de Medicina de Botucatu, Departamento de Neurologia, Psicologia e Psiquiatria, Botucatu SP, Brasil.

Correspondence: Gustavo José Luvizutto; Rua Capitão Domingos, 309; 38025-180 Uberaba MG, Brasil; E-mail: gluvizutto@gmail.com

Conflict of interest: There is no conflict of interest to declare.

Received 07 February 2018; Received in final form 28 June 2018; Accepted 29 June 2018.

Support: Fundação de Amparo à Pesquisa do Estado de São Paulo (FAPESP). Processo 2016/17914-3.
} 
Approximately $85 \%$ of individuals experience hemiparesis immediately after the stroke, particularly in an upper limb, and $55 \%-75 \%$ of these individuals have persistence of motor deficits, making it difficult to return to work and leisure, consequently worsening their quality of life ${ }^{5}$.

Epidemiological clinical studies have suggested that $33 \%-66 \%$ of stroke patients had no motor recovery after six months. Several techniques aiming to improve upper limb function are still being developed. However, the implementation of these techniques requires great team work, a high degree of specialization, and requires more time ${ }^{5,6}$. Currently, there are new approaches to rehabilitation, and virtual reality is still developing, with the objective of restoring the functional capacity of individuals after stroke as an easy, interactive, and low-cost intervention ${ }^{7.8}$.

The objective of stroke rehabilitation is to provide maximal physical, functional, and psychosocial recovery for the patients9. Comprehensive rehabilitation initiated early after stroke (within the first 24 hours) is generally accepted as being associated with better motor outcomes for these patients9. Strength training is an important part of the therapeutic process for upper-limb motor impairment after stroke ${ }^{10}$.

Virtual reality is defined as any hardware or software system that provides a simulated environment with real or imagined conditions that allow participating individuals to interact with the environment. The interaction is made by body movements using motion capture technology or by manipulating a device ${ }^{11}$. This interaction generates information necessary for proper understanding of the movement with particular emphasis on the upper limbs ${ }^{12}$. The technique consists of an avatar (graphic representation of the person) generated by the video game, where the individual manages a wireless control, directing the movement during the practice of different activities $^{5}$. This is a good option for rehabilitation for individuals with stroke due to the variety of nonimmersive video game systems developed by the entertainment industry for home use.

This wide availability makes virtual reality an accessible and inexpensive rehabilitation method for rehabilitation centers $^{13}$. Despite the ease of application, virtual reality therapy (VRT), added to conventional physical therapy has not been associated with a better outcome than recreational activity $^{13}$. Adverse events usually are mild and the main effects described are transient dizziness and headache, pain and numbness ${ }^{13,14}$. Time since the onset of stroke, severity of impairment, and the type of device (commercial or customized) usually do not influence the outcome ${ }^{14}$. However, the variable methodology is an important bias for these investigations ${ }^{14}$. Therefore, virtual reality is still a promising tool. Some authors have reported that VRT can be combined with conventional rehabilitation to improve upper limb function after stroke $e^{15,16}$. The clinical situations wherein VRT may best be used have not yet been established in the literature. Also, the exact mechanism of action of this treatment modality is not yet fully understood.
The objectives of this study were to evaluate the effects of VRT combined with conventional rehabilitation for upper limb function in the recovery of individuals after stroke. Neuroimaging characteristics that could be used as predictors of a better response to VRT were also investigated.

\section{METHODS}

\section{Participants, setting, and design}

This was a prospective clinical study that evaluated the effect of a VRT program at the Hospital das Clínicas, Medical School of São Paulo State University, Botucatu Campus between March, 2015 and July, 2016. The study was a convenience sample with consecutive patients.

\section{Inclusion criteria}

Patients older than 18 years, who had a first ischemic stroke and who were within the window of three to six months after the stroke were included in the study. The diagnosis of all participants was defined and confirmed by neuroimaging [computed tomography $(\mathrm{CT})$ or magnetic resonance imaging], and the level of motor function of the upper limb was equal or superior to that in the Chedoke-McMaster Stroke Assessment.

\section{Exclusion criteria}

Patients unable to cooperate, with a history of stroke, modified Rankin scale $(\mathrm{mRS})>2$, uncontrolled hypertension, unstable angina or recent myocardial infarction ( $<3$ months), those participating in another clinical study involving drugs or physical therapy, shoulder subluxation, or fractures of the upper limb were excluded.

\section{Clinical data and variables}

Neurological characteristics were collected through the National Institutes of Health Stroke Scale (NIHSS), mRS, Barthel Index, and Scandinavian Stroke Scale. The functional characteristics of the upper limb were evaluated using the Chedoke-McMaster scale, Box and Block Test, and upper limb subset of the Motor Assessment Scale. Quality of life was assessed using the Stroke Impact Scale version 3.0.

\section{Neurological characteristics}

1) NIHSS: aims to quantify neurological deficits through items that address the level of consciousness, speech, language, visual field, somatognosia, eye movement, strength, coordination, and sensitivity. The maximum score is 42 , indicating a high neurological score ${ }^{15}$;

2) mRS: aims to assess the degree of independence and determines whether the patient can provide self-care during activities of daily living ${ }^{17}$;

2) Barthel Index: aims to measure the functional independence of the individual in 10 activities: food, 
bathing, personal care, ability to dress, bowel rhythm, urinary rhythm, toilet use, transfers, mobility, and climbing stairs. The maximum score is 100 , indicating a high degree of functional independence ${ }^{17}$;

4) Scandinavian Stroke Scale: aims to quantify the severity of paresis and level of disability, with minimum and maximum scores of 2 and 58, indicating that the higher the score, the lower the neurological deficit ${ }^{18}$.

\section{Functional characteristics of upper limbs}

1) Chedoke-McMaster Stroke Assessment: ranges from 0 (worst degree of function) to 7 (best degree of function) and aims to classify the condition of the upper limb after stroke ${ }^{19}$;

2) Box and Block Test: evaluates upper limb dexterity using a box divided into two compartments. The patient is instructed to transfer cubes of $1 \mathrm{~cm}^{3}$ in diameter from one compartment to another in 60 seconds. Scored by the number of blocks transferred in three attempts; the greater the number of blocks transferred, the better the dexterity and function of the upper limb ${ }^{20}$;

3) Motor Assessment Scale: Upper limb function, hand movements, and advanced activities (dexterity) are evaluated by a qualitative scale staggered from 3 to 18, indicating that the higher the score the better the dexterity and function of the upper limb ${ }^{21}$.

\section{Quality of life scale}

Stroke Impact Scale: specifically evaluates the quality of life after stroke. It includes nine domains and the individuals' perception of their recovery ${ }^{22}$.

\section{Intervention}

Patients in the convenience sample were evaluated against the inclusion criteria by the principal investigator of the study.

After the selection, an evaluator, blinded to the study, defined the neurological, functional, and quality of life characteristics of the participants, and these results were considered the beginning of the rehabilitation. All patients received standard rehabilitation (30 minutes of physiotherapy and 30 minutes of occupational therapy). Subsequently, the patients underwent VRT. They were placed in a room with natural light, six meters away from the screen. They were instructed to remain in the orthostatic position, with the hand-held control on the affected side.

The games used were Wii Sports Tennis and Wii Sports Bowling, which work on the automatic motor mechanics of the affected limb, and the Cooking Mama package, a cooking game consisting of activities, such as preparing food and making meals, each for 20 minutes, with a total of 60 minutes of therapy for 20 sessions, held twice a week.

After the treatment, the same blinded evaluator performed the final evaluations of the neurological, functional, and quality of life characteristics of the individuals.

\section{Neuroimaging}

High-resolution CT scans performed during hospitalization in the post-stroke phase were used. For this analysis, only patients with volumetric images were included. The images were obtained on a 16 channels Toshiba Activion system with a maximum voxel size of $0.46 \times 0.46 \times 1.25 \mathrm{~mm}, 1.0$ second gantry rotation time, $120 \mathrm{kVp}$ and $190 \mathrm{~mA}$ and field of view of $240 \mathrm{~mm}$.

The lesions were semi-automatically segmented using the ITK-SNAP program ${ }^{23}$. Images and lesions were registered in the standard space using the Clinical Toolbox tools ${ }^{24}$ and SPM8 (Statistical Parametric Mapping) ${ }^{25}$ running on the MATLAB platform ${ }^{26}$. At this stage, the images were transformed into 1 $\mathrm{mm}$ isotropic voxels. After normalization, the images of individuals with right hemisphere lesions were flipped to the left. Finally, maps of image overlap, and location of damaged areas were performed using the MRIcron program ${ }^{27}$.

Gray matter lesions were mapped based on the Automated Anatomical Labeling atlas ${ }^{28}$. White matter changes were mapped using the Johns Hopkins University white matter tractography atlas ${ }^{29}$.

\section{Statistical analysis}

Statistical analysis was performed using the IBM SPSS Statistics" Version 21. A multivariate analysis was performed using the general linear model for repeated measures. The difference between pre- and post-intervention performances was compared. Age, sex, and treatment received in the acute phase (thrombolysis) were used as confounding factors. A $p$ value of $<0.05$ was considered statistically significant.

For statistical analysis of the images, the regions of interest derived from the atlas mentioned above and the NiiStat program were used. A voxel-based lesion-symptom mapping approach was employed for the neuroimaging analysis. This technique is able to analyze the relationship between tissue damage and behavior on a voxel-by-voxel basis ${ }^{30}$. Overlaid areas of structural abnormality (infarction) were correlated with the task performance. Therefore, NiiStat analyzes the segmented images (weighting all the regions of interest involved) and functional markers of the upper limb. To investigate the correlation between improvement or worsening in performance and changes in the image, the two clinical evaluations and the difference between them were used. This analysis was performed using the general linear model by applying a linear regression with a significance level of $\mathrm{p}<0.05$. Damaged voxels were considered dependent variables and performance scores were the independent variables. The results are standardized based on the group evaluated (Z score).

\section{Ethics approval and consent to participate}

This trial was approved by the Committee for Ethics in Research involving human subjects from the Botucatu Medical School. Upon inclusion, all patients or legal surrogates provided written informed consent in accordance with 
the Declaration of Helsinki II. All invited patients agreed to participate in the study.

\section{RESULTS}

Eighteen patients were included (eight women; mean age, $55.5 \pm 13.9$ years; mean \pm standard deviation). Nine patients underwent treatment with cerebral reperfusion. Fourteen patients presented with right neurological deficits. The mean mRS was $2.4 \pm 1.2$ and $1.4 \pm 1$ before and after the intervention, respectively, with a mean difference of $-1 \pm 0.8$. The Barthel Index score was $80.6 \pm 15.4$ and $92.5 \pm 9.4$ before and after the intervention, respectively, with a mean difference of $11.9 \pm 9.3$. The NIHSS scores were $3.6 \pm 2.6$ and $2 \pm 1.8$ before and after the intervention, respectively, with a mean difference of $-1.6 \pm 1.5$. Furthermore, the Scandinavian Stroke Scale evaluation showed a mean of $49.2 \pm 4.7$ and $54.1 \pm 3.9$ before and after the intervention, respectively, with a mean difference of $4.9 \pm 4$.1. No adverse events were reported. All scales showed a significant difference between the pre- and post-intervention stages $(\mathrm{p}<0.0001)$, and no interactions with sex, age, and treatment with cerebral reperfusion were observed. Table 1 summarizes the clinical findings.

All functional scales also showed a significant difference between the pre- and post-intervention stages, with the following results: Chedoke-McMaster scale with $\mathrm{p}=0.004$ and no interactions with sex, age, and thrombolytic treatment; Motor Assessment Scale item 6 (arm movement; p = 0.004) and no interactions; Motor Assessment Scale item 7 (hand movement; $p=0.011$ ) and no interactions; Motor Assessment Scale item 8 (advanced hand movement; $p=0.004$ ) and interaction with sex variable ( $\mathrm{p}=0.004)$; Box and Block Test with $\mathrm{p}<0.0001$ and no interactions.

With regard to the Stroke Impact Scale, the following results were obtained in the nine domains studied: strength (pre- vs. post-intervention; $28.8 \pm 10.1$ vs. $72.2 \pm 16.4$; $p=0.0004$ ), hand function ( $94.4 \pm 10.5 \mathrm{vs} .99 .3 \pm 1.7 ; \mathrm{p}=0.0041)$, daily life activities ( $62.8 \pm 11.0$ vs. $91.8 \pm 14.2$; $\mathrm{p}=0.0001)$, instrumental activities of daily living (95.0 \pm 13.3 vs. $98.4 \pm 6.7 ; p=0.248)$, mobility (61.6 \pm 16.2 vs. $79.5 \pm 9.4 ; \mathrm{p}=0.0004)$, communication (59.7 \pm 17.9 vs. $91.6 \pm 23.2 ; \mathrm{p}=0.0004)$, emotion (27.1 \pm 21.0 vs. $69.4 \pm 28.9$;

Table 1. Clinical features of 18 patients with stroke and upper limb impairment submitted to virtual reality therapy and conventional rehabilitation.

\begin{tabular}{lccc}
\hline Variable & $\mathrm{n}$ & Before VRT & After VRT* \\
\hline Age (years) & $55.5 \pm 13.9$ & & \\
Women & 8 & & $2.4 \pm 1.2$ \\
Reperfusion treatment & 9 & $80.6 \pm 15.4$ & $1.4 \pm 1$ \\
Modified Rankin Scale & & $3.6 \pm 2.6$ & $92.5 \pm 9.4$ \\
Barthel index & & $49.2 \pm 4.7$ & $2 \pm 1.8$ \\
NIHSS & & $54.1 \pm 3.9$ \\
\hline Scandinavian Stroke Scale & & \\
\hline
\end{tabular}

VRT:Virtual reality therapy; NIHSS: National Institutes of Health Stroke Scale; ${ }^{*}$-values $<0.0001$

Table 2. Functional and quality of life results obtained before and after virtual reality therapy in 18 patients with stroke and upper limb deficit.

\begin{tabular}{|c|c|c|c|}
\hline Variable & Before VRT & After VRT & p-value \\
\hline \multicolumn{4}{|c|}{ Functional results } \\
\hline Chedoke-McMaster Stroke Assessment Arm & $4.1 \pm 1.9$ & $5 \pm 1.6$ & 0.004 \\
\hline Chedoke-McMaster Stroke Assessment - Hand & $3.6 \pm 1.9$ & $4.7 \pm 1.8$ & $<0.0001$ \\
\hline Motor Assessment Scale - item 6 & $3.6 \pm 2.3$ & $4.6 \pm 1.8$ & 0.004 \\
\hline Motor Assessment Scale - item 7 & $3.3 \pm 2.3$ & $4.1 \pm 2.2$ & 0.011 \\
\hline Motor Assessment Scale - item 8 & $3 \pm 2.6$ & $3.7 \pm 2.3$ & 0.004 \\
\hline Box and Block Test & $18.9 \pm 14.8$ & $26.3 \pm 16$ & $<0.0001$ \\
\hline \multicolumn{4}{|c|}{ Quality of life } \\
\hline Strength & $28.8 \pm 10.1$ & $72.2 \pm 16.4$ & 0.0004 \\
\hline Hand function & $94.4 \pm 10.5$ & $99.3 \pm 1.7$ & 0.041 \\
\hline Daily living activities & $62.8 \pm 11.0$ & $91.8 \pm 14.2$ & 0.0001 \\
\hline Instrumental daily living activities & $95.0 \pm 13.3$ & $98.4 \pm 6.7$ & 0.248 \\
\hline Mobility & $61.6 \pm 16.2$ & $79.5 \pm 9.4$ & 0.0004 \\
\hline Communications & $59.7 \pm 17.9$ & $91.6 \pm 23.2$ & 0.0004 \\
\hline Emotions & $27.1 \pm 21.0$ & $69.4 \pm 28.9$ & 0.0001 \\
\hline Memory & $93.6 \pm 24.9$ & $97.4 \pm 23.7$ & 0.0736 \\
\hline Social interaction & $60.6 \pm 23.0$ & $77.1 \pm 23.0$ & 0.0019 \\
\hline
\end{tabular}

VRT:Virtual reality therapy. 
$\mathrm{p}=0.0001)$, memory (93.6 \pm 24.9 vs. $97.4 \pm 23.7 ; \mathrm{p}=0.0736)$, and social participation $(60.6 \pm 23.0$ vs. $77.1 \pm 23.0$; $p=0.0019)$. Table 2 summarizes the stroke impact in the functional and quality of life before and after intervention with VRT.
The mean volume of lesions observed among patients was $24,172 \pm 17,302 \mathrm{~mm}^{3}$. The mean volume of white and gray matter damage was $3,420 \pm 2,645 \mathrm{~mm}^{3}$ and $21,012 \pm 15,500 \mathrm{~mm}^{3}$, respectively. The main structures affected are shown in Tables 3 and 4.

Table 3. Main white matter cerebral structures injured in nine patients with stroke submitted to virtual reality rehabilitation. The anatomical structure was obtained using the Johns Hopkins University white matter tractography atlas. ${ }^{29}$ The volumes indicates the amount of damage in the structure (sum of affected volume for all patients) followed by the mean and variance.

\begin{tabular}{|c|c|c|}
\hline Anatomical structure & Volume $\left(\mathrm{mm}^{3}\right)$ & $\mathrm{N}$ \\
\hline Upper longitudinal fasciculus & 6,$715 ; 1,343 \pm 1326(8-2,874)$ & 5 \\
\hline External capsule & 5,$820 ; 970 \pm 1454(55-3,506)$ & 6 \\
\hline Superior corona radiata & 5,$406 ; 901 \pm(26-2,108)$ & 6 \\
\hline Posterior thalamic radiation & 2,$240 ; 746 \pm 773(111-1,608)$ & 3 \\
\hline Splenium of corpus callosum & 2,$134 ; 711 \pm 878(26-1,702)$ & 3 \\
\hline Posterior limb of internal capsule & 1,$949 ; 390 \pm 356(64-983)$ & 5 \\
\hline Longitudinal and fronto-occipital inferior & 1,$709 ; 569 \pm 522(80-1,120)$ & 3 \\
\hline Anterior corona radiata & 1,$635 ; 545 \pm 908(8-1,594)$ & 3 \\
\hline Posterior corona radiata & 1,$499 ; 250 \pm 267(19-749)$ & 6 \\
\hline Cingulum & $896 ;{ }^{*}$ & 1 \\
\hline Retrolenticular internal capsule & $587 ; 146 \pm 265(6-545)$ & 4 \\
\hline Fornix & $585 ; 146 \pm 172(7-391)$ & 4 \\
\hline Anterior limb of internal capsule & $547 ; 136 \pm 142(15-317)$ & 4 \\
\hline Superior fronto-occipital fasciculus & $315 ; 105 \pm 117(17-238)$ & 3 \\
\hline Body of corpus callosum & $75 ; 37 \pm 2(36-39)$ & 2 \\
\hline Tapetum of corpus callosum & $66 ; 33 \pm 31(11-55)$ & 2 \\
\hline
\end{tabular}

Table 4. Main gray matter cerebral structures injured in nine patients with stroke submitted to virtual reality rehabilitation. The anatomical structure was obtained using the Automated Anatomical Labeling atlas ${ }^{28}$. The volumes indicates the amount of damage in the structure (sum of affected volume for all patients) followed by the mean and variance.

\begin{tabular}{|c|c|c|}
\hline Anatomical structure & Volume $\left(\mathrm{mm}^{3}\right)$ & $\mathrm{N}$ \\
\hline Insula & 23,$765 ; 3,960 \pm 5,228(13-11,678)$ & 6 \\
\hline Inferior temporal gyrus & 20,$292 ; 1,844 \pm 2,038(48-5,285)$ & 4 \\
\hline Inferior frontal gyrus & 17,$025 ; 2,837 \pm 2,038(462-6,094)$ & 2 \\
\hline Postcentral gyrus & 17,$011 ; 5,670 \pm 5,263(761-11,228)$ & 3 \\
\hline Precentral gyrus & 13,$999 ; 3,499 \pm 3,892(63-8,926)$ & 4 \\
\hline Fusiform gyrus & 12,$288 ; 4,096 \pm 6,994(53-12,172)$ & 3 \\
\hline Rolandic operculum & 12,$191 ; 2,438 \pm 3,760(9-8,958)$ & 5 \\
\hline Inferior parietal lobe & 10,$098 ; 3,366 \pm 2,552(557-5,542)$ & 3 \\
\hline Giro lingual & 8,$827 ; *$ & 1 \\
\hline Supramarginal gyrus & 8,$618 ; 2,872 \pm 2,508(126-5043)$ & 3 \\
\hline Putamen & 6,$555 ; 1,638 \pm 2,417(137-5,248)$ & 4 \\
\hline Middle occipital gyrus & 6,$214 ; 2,071 \pm 1,325(1,181-3,595)$ & 3 \\
\hline Calcarine & 4,$216 ; 2,108 \pm 2,865(82-4,134)$ & 2 \\
\hline Hippocampus & 4,$005 ; 1,335 \pm 1,090(205-2,381)$ & 3 \\
\hline Inferior occipital gyrus & 3,$627 ; 1,813 \pm 2,556(6-3,621)$ & 2 \\
\hline Thalamus & 3,$106 ; 776 \pm 758(7-1819)$ & 2 \\
\hline Giro parahippocampal & 3,$073 ; 1,536 \pm 1191(694-2,379)$ & 2 \\
\hline Superior cerebellum & 3,$035 ; *$ & 1 \\
\hline Superior parietal lobe & 2,$161 ; 720(23-2007)$ & 3 \\
\hline Heschl's gyrus & 1,$828 ; 609 \pm 746(1-1,442)$ & 3 \\
\hline Pallidum & 1,$581 ;{ }^{\star}$ & 1 \\
\hline Cuneus & 1,$114 ; 557 \pm 738(35-1079)$ & 2 \\
\hline Middle frontal gyrus & 1,$095 ; 365 \pm 607(7-1066)$ & 3 \\
\hline Caudate & $954 ; 318 \pm 33(279-339)$ & 3 \\
\hline Pre cuneus & $877 ; 292 \pm 499(4-869)$ & 3 \\
\hline Angular gyrus & $817 ; 408 \pm 289(133-684)$ & 2 \\
\hline Paracentral lobule & $356 ;{ }^{*}$ & 1 \\
\hline Cingulum & $165 ; 82 \pm 103(9-156)$ & 2 \\
\hline Superior occipital gyrus & $154 ; 77 \pm 49(42-112)$ & 2 \\
\hline Amygdala & $36 ;^{*}$ & 1 \\
\hline Superior frontal gyrus & $25 ; *$ & 1 \\
\hline
\end{tabular}

Volume in $\mathrm{mm}^{3}$ : sum of total affected volume in all patients followed by mean, standard deviation, minimal and maximal values (when available); n: number of patients with lesion in the structure; *: mean not available (only one patient). 
Statistical analyses of white matter structures analyzed 18 affected regions of the 48 available in the template atlas (Figure A). The following correlations were observed: Chedoke-McMaster (arm) in the two evaluations with the posterior portion of the internal capsule $(Z=-2.2$ and $Z=-3)$ and the difference between the evaluations with the inferior temporal gyrus $Z=2.3$ ); Chedoke-McMaster (hand) in the evaluation after intervention with the posterior portion of the internal capsule $(Z=-2.5)$; Motor Assessment Scale item 6 in the difference of the evaluations with the inferior frontal gyrus triangular portion $(Z=2.6)$, medial and lateral orbitofrontal gyri $(Z=2.4$ and 2.4$)$ and caudate nucleus $(Z=2.2)$; Motor Assessment Scale item 8 in the two evaluations with the posterior portion of the internal capsule $(Z=-3.3$ and -2.5); Box and Block Test in the two evaluations with the posterior portion of the internal capsule $(Z=-2.4$ and -2.7$)$.

For the gray matter, 52 affected regions of the 116 regions available in the template atlas were evaluated (Figure B). The correlations observed were the following: Chedoke-McMaster scale (arm) in the first evaluation with the middle occipital gyrus $(\mathrm{Z}=2.2)$ and the difference between the assessments with the amygdala $(Z=2.3)$; Chedoke-McMaster (hand) in the first evaluation with the middle occipital gyrus $(Z=2.3)$; Motor Assessment Scale item 6 in the difference between the evaluations and the superior frontal gyrus orbital portion $(Z=2.6)$, inferior frontal gyrus triangular and orbital portions $(Z=2.6$ and 2.5$)$, olfactory gyrus $(Z=2.3)$, middle frontal gyrus $(Z=2.3)$, gyrus rectus $(Z=2.3)$, and anterior cingulate gyrus $(Z=2.3)$.

\section{DISCUSSION}

The present study evaluated the effect of VRT combined with conventional rehabilitation on a series of stroke patients, showing positive results in improving the functionality of the upper limb.

Improvement was observed in all aspects of the neurological characteristics evaluated through the NIHSS, mRS, Barthel Index, and Scandinavian Stroke Scale. Therefore, VRT may be considered an important adjunctive therapy for the treatment of clinical changes that affect functional

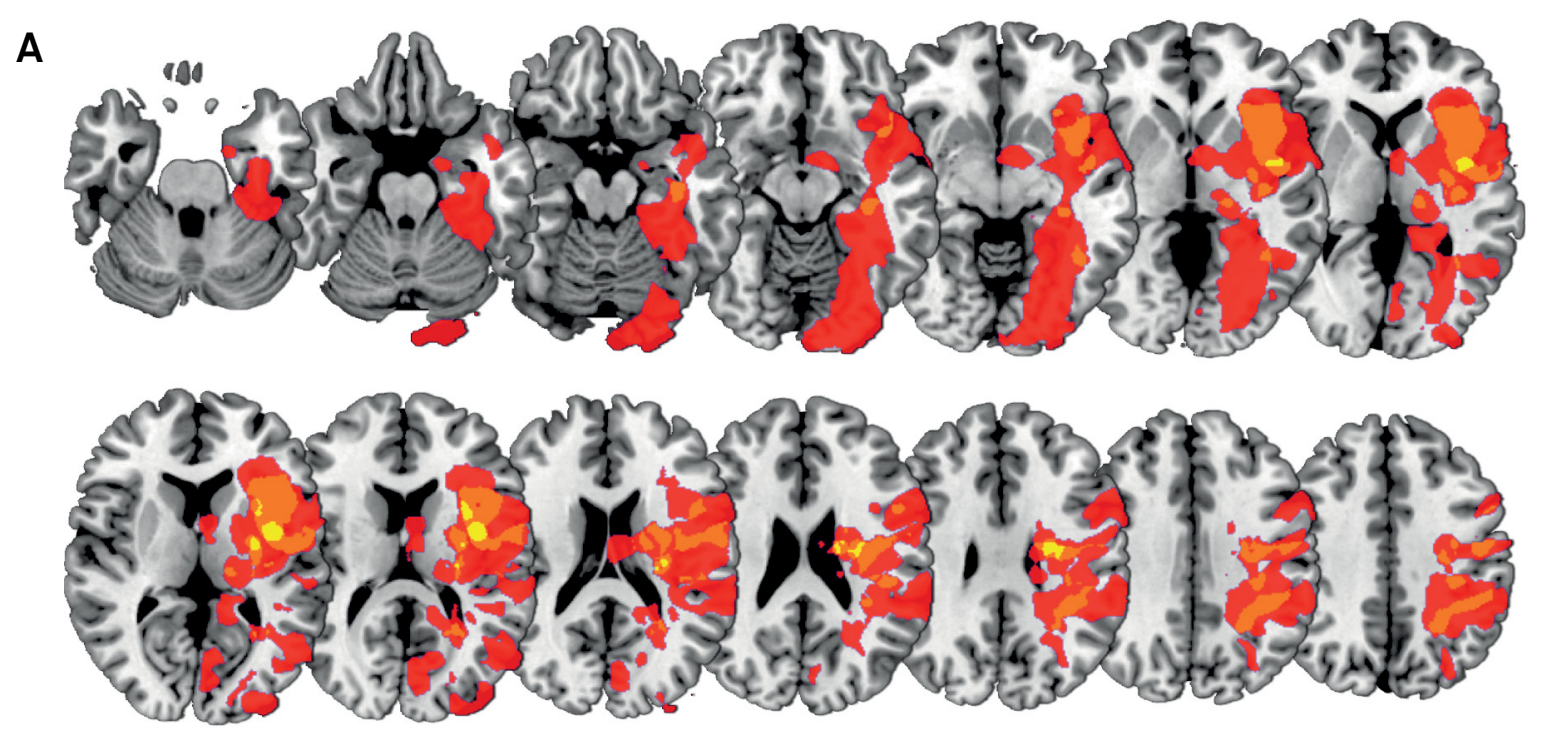

B
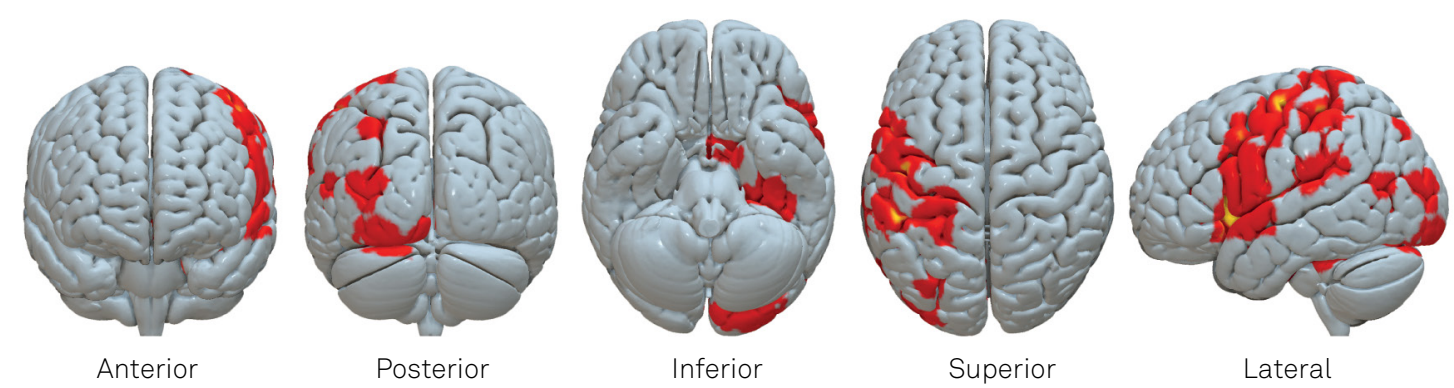

Number of patients

1

3

Figure. Brain areas affected in nine patients with stroke and upper limb impairment underwent virtual reality therapy (A). Findings are overlaid in a template of axial magnetic resonance image slices and in a three-dimensional model of the brain (B). The color code bar in the inferior portion of the figure indicates the number of patients with the area injured. 
independence and compromise the quality of life of patients with stroke. Virtual reality appears to have a positive impact on brain plasticity, leading to the reduction of motor deficits. Previous studies have shown that repetition and movement intensity act directly as promoters of neural plasticity $^{31}$. In this study, the activities proposed for rehabilitation were repetitive movements and exposure to tasks requiring specific functions.

Virtual reality therapy combined with conventional rehabilitation also showed a positive impact on the functionality and dexterity of the upper limb. Improvement was observed in all upper limb functional scales. Virtual reality is considered a computer technology that simulates motor learning ${ }^{32}$. The mechanism is related to a large number of repetitions of the task, generating increased feedback. The use of virtual reality requires substantial control of the upper limb and hand grip. This control is through neural mechanisms of feedback. When using a visual reference, achievement of a precise and functional goal while performing complex movements with the upper limb (reaching or targeting) requires great dexterity. During this process, areas related to function are activated in the central nervous system with progressive improvement of motor learning ${ }^{33}$.

Adult brain neurons often increase the rate of firing in the sensorimotor cortex regions when participants observe or perform mirrored movements ${ }^{34}$. The activation of this system, called mirror neurons, includes areas of the frontal, parietal, and temporal lobes, and may induce cortical reorganization after injury to the central nervous system. Virtual reality involves the use of technology in three dimensions with a computerized scenario, allowing the individual to interact with the environment. This procedure increases the rate of firing by the mirror neurons, capturing the interactive movement performed by the avatar ${ }^{35,36}$.

In studies with normal participants, the use of VRT was associated with increased activation of the primary sensorimotor cortex on the contralateral side, which may have led to expanded motor references for daily activities and improvement in upper limb dexterity ${ }^{37,38}$.

With regard to the quality of life, almost all items of the Stroke Impact Scale showed statistical significance. Therefore, VRT combined with conventional rehabilitation improved the quality of life of patients with stroke. This improvement, in part, is a reflex of the return to daily routine activities with minimal interference from the neurological deficit ${ }^{39}$. In addition, VRT is a fun method, generating better interaction between therapists and patients. This collaboration makes therapy less exhausting than conventional methods and generates motivational feedback ${ }^{40}$. Consequently, a positive effect was noted on cognition and physical function.

A positive relationship was observed between the differences in the assessments of the function of the upper limb in the shoulder and elbow movements with lesions in the inferior frontal gyrus triangular portion, medial and lateral orbitofrontal gyri, and caudate nucleus. These structures are involved in the memorization of movements and in performing more complex movements automatically. These findings may indicate that these structures have greater neuroplasticity and, therefore, they have a better response to VRT when compromised ${ }^{41}$.

Similarly, the Motor Assessment Scale item 6 was also positively associated with lesions in the superior frontal gyrus orbital portion, frontal inferior gyrus triangular and orbital portion, olfactory gyrus, middle frontal gyrus, gyrus rectus, and anterior cingulate, showing that VRT combined with conventional rehabilitation improved the planning and execution of movement in these patients ${ }^{41}$.

Statistical analysis between white matter lesions and functionality and dexterity showed a negative correlation with the posterior portion of the internal capsule. The internal capsule comprises transmission axons to the cortex, and a lesion in this structure is responsible for most motor changes following stroke. The internal capsule is supplied by the middle cerebral artery. Damage in this region can result in motor impairment, particularly in the upper $\operatorname{limbs}^{42,43}$. The negative correlation observed in the two evaluations using the Motor Assessment Scale, Box and Block Test, and Chedoke-McMaster (arm) suggest that this structure can be used as a marker for the indication of VRT combined with conventional rehabilitation. The negative correlation of these evaluations is related to less evidence of improvement and an intensification of the rehabilitation process may be required.

One of the limitations of this study was the small number of participants. Recruitment of patients was time consuming because of the strict inclusion criteria. The vast majority of patients treated at stroke units have a wide variety of comorbidities and extensive diseases preventing their inclusion. These factors limited the inclusion of participants. Another drawback was the lack of a control group. From the data obtained in this preliminary investigation, we hypothesize that VRT is safe and may be useful as adjunctive therapy. Additional studies comparing conventional rehabilitation and VRT are needed.

With regard to neuroimaging, the number of patients was smaller because not all patients underwent 3D CT. In addition, the quality of the examination had to be sufficient for accurate delimitation of the injured area. These issues were important limitations of this investigation and, consequently, results should be interpreted cautiously.

In patients with stroke treated with conventional rehabilitation and VRT, significant improvement in clinical characteristics and upper limb function was observed, as well as an improvement in the patient's perception of quality of life. Subcortical strokes with involvement of the posterior portion of the internal capsule presented the worst response to therapy. 
1. Sacco RL, Kasner SE, Broderick JP, Caplan LR, Connors JJ, Culebras A et al. An updated definition of stroke for the 21 st century: a statement for healthcare professionals from the American Heart Association/American Stroke Association. Stroke. 2013 Jul;44(7):2064-89. https://doi.org/10.1161/STR.0b013e318296aeca

2. Abdul Aziz AF, Mohd Nordin NA, Ali MF, Abd Aziz NA, Sulong S, Aljunid SM. The integrated care pathway for post stroke patients (iCaPPS): a shared care approach between stakeholders in areas with limited access to specialist stroke care services. BMC Health Serv Res. 2017 Jan;17(1):35. https://doi.org/10.1186/s12913-016-1963-8

3. Donnan GA, Fisher M, Macleod M, Davis SM. Stroke. Lancet. 2008 May;371(9624):1612-23. https://doi.org/10.1016/S0140-6736(08)60694-7

4. Nijland RH, Wegen EE, Harmeling-Van Der Wel BC, Kwakkel G. Presence of finger extension and shoulder abduction within 72 hours after stroke: The EPOS cohort study stroke predicts functional recovery: Early prediction of functional outcome. Stroke. 2010;41(4):745-50. https://doi.org/10.1161/STROKEAHA.109.572065

5. Saposnik G, Mamdani M, Bayley M, Thorpe KE, Hall J, Cohen LG et al. Effectiveness of Virtual Reality Exercises in STroke Rehabilitation (EVREST): rationale, design, and protocol of a pilot randomized clinical trial assessing the Wii gaming system. Int J Stroke. 2010 Feb;5(1):47-51. https://doi.org/10.1111/j.1747-4949.2009.00404.x

6. Prochnow D, Bermúdez i Badia S, Schmidt J, Duff A, Brunheim S, Kleiser $\mathrm{R}$ et al. A functional magnetic resonance imaging study of visuomotor processing in a virtual reality-based paradigm: Rehabilitation Gaming System. Eur J Neurosci. 2013 May;37(9):14417. https://doi.org/10.1111/ejn.12157

7. You SH, Jang SH, Kim YH, Hallett M, Ahn SH, Kwon YH et al. Virtual reality-induced cortical reorganization and associated locomotor recovery in chronic stroke: an experimenter-blind randomized study. Stroke. 2005 Jun;36(6):1166-71. https://doi.org/10.1161/01. STR.0000162715.43417.91

8. Cameirão MS, Badia SB, Oller ED, Verschure PF. Neurorehabilitation using the virtual reality based rehabilitation gaming system: methodology, design, psychometrics, usability and validation.J Neuroeng Rehabil. 2010;7:48. https://doi.org/10.1186/1743-0003-7-48

9. Good DC, Bettermann K, Reichwein RK. Stroke rehabilitation. Continuum (Minneap Minn). 2011;17(3 Neurorehabilitation):545-67. https://doi.org/10.1212/01.CON.0000399072.61943.38

10. Harris JE, Eng JJ. Strength training improves upper-limb function in individuals with stroke: a meta-analysis. Stroke. 2010 Jan;41(1):13640. https://doi.org/10.1161/STROKEAHA.109.567438

11. Lange B, Koenig S, Chang CY, McConnell E, Suma E, Bolas M et al. Designing informed game-based rehabilitation tasks leveraging advances in virtual reality. Disabil Rehabil. 2012;34(22):1863-70. https://doi.org/10.3109/09638288.2012.670029

12. Cameirão MS, Badia SB, Duarte E, Frisoli A, Verschure PF. The combined impact of virtual reality neurorehabilitation and its interfaces on upper extremity functional recovery in patients with chronic stroke. Stroke. 2012 Oct;43(10):2720-8. https://doi.org/10.1161/STROKEAHA.112.653196

13. Saposnik G, Cohen LG, Mamdani M, Pooyania S, Ploughman M, Cheung $D$ et al. Efficacy and safety of non-immersive virtual reality exercising in stroke rehabilitation (EVREST): a randomised, multicentre, single-blind, controlled trial. Lancet Neurol. 2016 Sep;15(10):1019-27. https://doi.org/10.1016/S1474-4422(16)30121-1

14. Laver KE, Lange B, George S, Deutsch JE, Saposnik G, Crotty M. Virtual reality for stroke rehabilitation. Cochrane Database Syst Rev. 2017 Nov;11(11):CD008349.https://doi.org/10.1002/14651858.CD008349.pub2

15. Așkın A, Atar E, Koçyiğit H, Tosun A. Effects of Kinect-based virtual reality game training on upper extremity motor recovery in chronic stroke. Somatosens Mot Res. 2018 Mar;35(1):25-32. https://doi.org/10.1080/08990220.2018.1444599
16. Kiper P, Szczudlik A, Agostini M, Opara J, Nowobilski R, Ventura L et al. Virtual reality for upper limb rehabilitation in subacute and chronic stroke: a randomized controlled trial. Arch Phys Med Rehabil. 2018 May;99(5):834-842.e4. https://doi.org/10.1016/j.apmr.2018.01.023

17. Cincura C, Pontes-Neto OM, Neville IS, Mendes HF, Menezes DF, Mariano DC et al. Validation of the National Institutes of Health Stroke Scale, modified Rankin Scale and Barthel Index in Brazil: the role of cultural adaptation and structured interviewing. Cerebrovasc Dis. 2009;27(2):119-22. https://doi.org/10.1159/000177918

18. Luvizutto GJ, Monteiro TA, Braga G, Pontes-Neto OM, Resende LAL, Bazan R. Validation of the scandinavian stroke scale in a multicultural population in Brazil. Cerebrovasc Dis Extra. 2012 Jan;2(1):121-6. https://doi.org/10.1159/000345948

19. Gowland C, Stratford P, Ward M, Moreland J, Torresin W, Van Hullenaar S et al. Measuring physical impairment and disability with the Chedoke-McMaster Stroke Assessment. Stroke. 1993 Jan;24(1):58-63. https://doi.org/10.1161/01.STR.24.1.58

20. Mathiowetz V, Volland G, Kashman N, Weber K. Adult norms for the Box and Block Test of manual dexterity. Am J Occup Ther. 1985 Jun;39(6):386-91. https://doi.org/10.5014/ajot.39.6.386

21. Miller KJ, Slade AL, Pallant JF, Galea MP. Evaluation of the psychometric properties of the upper limb subscales of the Motor Assessment Scale using a Rasch analysis model. J Rehabil Med. 2010 Apr;42(4):315-22. https://doi.org/10.2340/16501977-0519

22. Carod-Artal FJ, Coral LF, Trizotto DS, Moreira CM. The stroke impact scale 3.0: evaluation of acceptability, reliability, and validity of the Brazilian version. Stroke. 2008 Sep;39(9):2477-84. https://doi.org/10.1161/STROKEAHA.107.513671

23. Yushkevich PA, Piven J, Hazlett HC, Smith RG, Ho S, Gee JC et al. Userguided $3 \mathrm{D}$ active contour segmentation of anatomical structures: significantly improved efficiency and reliability. Neuroimage. 2006 Jul;31(3):1116-28. https://doi.org/10.1016/j.neuroimage.2006.01.015

24. Rorden C, Bonilha L, Fridriksson J, Bender B, Karnath HO. Age-specific CT and MRI templates for spatial normalization. Neuroimage. 2012 Jul;61 (4):957-65. https://doi.org/10.1016/j.neuroimage.2012.03.020

25. Friston KJ, Penny WD, Ashburner JK, Stefan J, Nichols TE. Statistical parametric mapping: the analysis of functional brain images. London: Elsevier; 2006.

26. Matlab. Statistics toolbox release. Natick: The Mathworks; 2012.

27. Rorden C, Brett M. Stereotaxic display of brain lesions. Behav Neurol. 2000;12(4):191-200. https://doi.org/10.1155/2000/421719

28. Tzourio-Mazoyer N, Landeau B, Papathanassiou D, Crivello F, Etard O, Delcroix $\mathrm{N}$ et al. Automated anatomical labeling of activations in SPM using a macroscopic anatomical parcellation of the mni MRI singlesubject brain. 2002;15(1):273-89. https://doi.org/10.1006/nimg.2001.0978

29. Mori S, Wakana S, Nagae-Poetscher LM, Zijl PCM. MRI Atlas of human white matter. Amsterdam: Elsevier; 2005.

30. Bates E, Wilson SM, Saygin AP, Dick F, Sereno MI, Knight RT et al. Voxel-based lesion-symptom mapping. Nat Neurosci. 2003 May;6(5):448-50. https://doi.org/10.1038/nn1050

31. Kleim JA, Jones TA. Principles of experience-dependent neural plasticity: implications for rehabilitation after brain damage. J Speech Lang Hear Res. 2008 Feb;51(1):S225-39. https://doi.org/10.1044/1092-4388(2008/018)

32. Sisto SA, Forrest GF, Glendinning D. Virtual reality applications for motor rehabilitation after stroke. Top Stroke Rehabil. 2002;8(4):1123. https://doi.org/10.1310/YABD-14KA-159P-MN6F

33. Shumway-Cook A, Woollacott M. Motor control: theory and practical applications. 2nd ed. Maryland: Lippincott Williams \& Wilkins; 2001.

34. Eng K, Siekierka E, Pyk P, Chevrier E, Hauser Y, Cameirao $M$ et al. Interactive visuo-motor therapy system for stroke rehabilitation. Med Biol Eng Comput. 2007 Sep;45(9):901-7. https://doi.org/10.1007/s11517-007-0239-1 
35. August K, Lewis JA, Chandar G, Merians A, Biswal B, Adamovich S. FMRI analysis of neural mechanisms underlying rehabilitation in virtual reality: activating secondary motor areas. Conf Proc IEEE Eng Med Biol Soc. 2006;1(1):3692-5. https://doi.org/10.1109/IEMBS.2006.260144

36. Small SL, Buccino G, Solodkin A. The mirror neuron system and treatment of stroke. Dev Psychobiol. 2012 Apr;54(3):293-310. https://doi.org/10.1002/dev.20504

37. Franceschini M, Agosti M, Cantagallo A, Sale P, Mancuso M, Buccino G. Mirror neurons: action observation treatment as a tool in stroke rehabilitation. Eur J Phys Rehabil Med. 2010 Dec;46(4):517-23.

38. Praamstra P, Torney L, Rawle CJ, Miall RC. Misconceptions about mirror-induced motor cortex activation. Cereb Cortex. 2011 Aug;21(8):1935-40. https://doi.org/10.1093/cercor/bhq270

39. Reid D, Hirji T. The influence of a virtual reality leisure intervention program on the motivation of older adult stroke survivors: a pilot study. Phys Occup Ther Geriatr. 2004;21(4):1-19. https://doi.org/10.1080/J148v21n04_01

40. Chao YY, Scherer YK, Montgomery CA. Effects of using Nintendo Wii ${ }^{\mathrm{TM}}$ exergames in older adults: a review of the literature. J Aging Health. 2015 Apr;27(3):379-402. https://doi.org/10.1177/0898264314551171

41. Yang M, Yang YR, Li HJ, Lu XS, Shi YM, Liu B et al. Combining diffusion tensor imaging and gray matter volumetry to investigate motor functioning in chronic stroke. PLoS One. 2015 May;10(5):e0125038. https://doi.org/10.1371/journal.pone.0125038

42. Barlow SJ. Identifying the brain regions associated with acute spasticity in patients diagnosed with an ischemic stroke. Somatosens Mot Res. 2016 Jun;33(2):104-11. https://doi.org/10.1080/08990220.2016.1197114

43. Puentes S, Kaido T, Hanakawa T, Ichinohe N, Otsuki T, Seki K. Internal capsule stroke in the common marmoset. Neuroscience. 2015 Jan;284(284):400-11. https://doi.org/10.1016/j.neuroscience.2014.10.015 